\title{
Sulfato de Magnesio Intra-Raquídeo en la Eclampsia
}

Doctor Rafaei. Arnedo Ramos

de la Facultad de Medicina de Cartagena.

La acción del Sulfato de Magnesio se debe al ión Magnesio; que como sabemos es uno de los componentes del sistema nervioso al cual debe su mayor n) menor grado de excitabilidad. El suero sanguineo contiene aproximadamente de dos a tres miligramos de magnesio.

Es un medicamento antiespasmódico debido a que su presencia inhibe la excitabilidad de la célula nerviosa, la cual cuando está sobrecargada de él, no responde o responde muy lentamente a los diversos estimulos tanto exter. nos como internos. Esto se ha demostrado experimentalmente con ratas alimentadas con una ración que no contenga magnesio; al cabo de unos 10 días éstas mueren en medio de accesos convulsivos. Al reducir el porcentaje normal de! magnesio en la sangre, primeramente se observan sacudidas musculares y después convulsiones. Su acción es completamente antagónica a la del calcio ef cual excita la célula, determinando contracciones al menor excitante. La acción anticonvulsivante del Sulfato de Magnesio se dobe a que es un depresor general del sistema nervioso, es decir, que disminuye la actividad funcional do éste. Cuando su porcentaje sanguíneo alcanza de 0.1 a $0.12 \%$ actúa como anestésico.

Basándose en estas propiedades del Magnesio fue que Meltzer y Auer se decidieron a usarlo para el tratamiento de las convulsiones eclámpticas, habićndose escogido entre sus sales el Sulfato, d cual usaron en concentraciones que variaban del 10 al $25 \%$ y ukaron la vía subcutánea y endovenosa, repitiendo la invección cuantas veces fuera necesario; ellos mo usaton la vio raquider cual tiene la rent ia de actuar rápidamente que es lo importante y necesario, detides a que el medicamento entra en contucto directo con el Sistema Nervios"

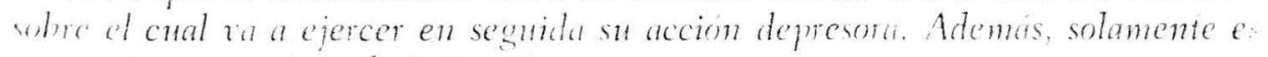
wecestrien poner una solu injeccion. 
Dorsett llegó a inyectar endovenosamente 100 c.c. de una solución al 25\% o sea 25 gramos en 12 horas sin observar accidente alguno. Pero no es cierto que este medicamento sea inocuo; pues un exceso de medicamento es capaz de producir la muerte por parálisis del centro bulbar respiratorio. Así, que no vaya a creerse que se pueden inyectar grandes cantidades sin que corra peligro la paciente; ahora bien, la cantidad que yo inyecto es de 5 c.c. de una solución al 20\%; o sea 1 gr.; que comparado con las grandes cantidades que ellos dicen, se deduce que en ningún momento puede poner en peligro la vida de la paciente.

Es cierto que se ha imputado a la punción raquídea diversos accidentes graves, incluso la muerte, pero en mis casos sólo se ha observado vómitos, una pasajera raquialgia, que duró tan sólo mientras la paciente no entró en estado de somnolencia, y parálisis del esfinter del ano y del vesical, pero ésta fue inmediata a la inyección o sea temporal; después todo se normaliź́.

Veamos cuales son los incidentes y secuelas de la punción raquídea.

InCIDENTES. - Se deben a la falta de técnica en la punción, a falta de pureza del producto a inyectar y a veces a irregularidades vertebrales de la paciente. La acción hipotensora es la responsable de las náuseas, los vómitos, la palidez y los sudores, pero esto pasa poco tiempo después sin causar ningún trastorno.

Entre los accidentes que deben ser siempre bien conocidos están:

Síncope: Poco tiempo después de haber hecho la punción lumbar comienza una bradipnea acompañada de hipotensión, algidez, palidez; los movimientos respiratorios siguen disminuyendo de frecuencia poco a poco lo que nos anuncia la inminencia del síncope respiratorio por parálisis del centro bulbar respiratorio. El corazón continúa latiendo, mas si la medicación de emergencia no logra hacer reaparecer la respiración viene el síncope cardíaco a complicar el cuadro clínico y el sujeto muere. Este accidente es muy raro. La paciente debe ponerse en posición horizontal caso que sobrevenga el síncope, además, debe hacerse respiración artificial.

Entre las secuelas de la punción raquídea están la cefalalgia, la hipertermia, los vómitos, raquialgia y retención urinaria. Solamente esta última se ha presentado en mis observaciones pero ha cedido rápidamente al tratamiento con tintura de nuez vómica y aplicación de bolsas tibias en el hipogastrio. Más excepcionales son las parálisis de los miembros inferiores, la meningomielitis, la oftalmoplejía, los trastornos psíquicos, tróficos y esfinterianos permanentes y la meningitis. Una solución de Sulfato de Magnesio al $20 \%$ que es la que yo uso es hipérbata con relación al líquido céfalo-raquídeo, por tanto tiende a descender en el espacio subaracnoideo. Por experimentos ya hechos se ha concluído que cualquier substancia introducida en el espacio sub-aracnoideo se fija en las partes periféricas de la medula, en la porción intra-aracnoidea de las raices raquídeas, en la zona de Lissauer y en los ganglios espinales. En todo caso, se necesita que haya el contacto directo entre el tejido nervioso y el líquido inyectado para que éste actúce. Pero ha solución de Sultato de Magnesio infectada también actúa sobre los rami-comnicantes del simpático produciendo una pará. 
lisis de los nervios vasocontrictores y por consiguiente una vasodilatación con la consecuencia lógica de un descenso de la presión arterial, y con este descenso la desaparición de la cefalalgia. Ahora bien, como el Sulfato de Magnesio es un depresor del sistema nervioso al fijarse en la medula disminuye su excitabilidad, de aquí que primeramente la paciente antes de entrar en somnolencia se encuentra en relajación muscular e indifirente a todo lo que acontece a su lado. Como a medida que transcurre el tiempo se van mezclando en toda su extensión el líquido céfalo-raquídeo con la solución de Sulfato de Magnesio, éstc va actuando sobre mayor extensión del tejido nervioso hasta que finalmente llega al cerebro donde actúa sobre la zona pre-rolándica y los centros corticales cons, cientes de la personalidad, quedando tan sólo en función los centros sub-corticales o de las funciones no conscientes.

El tiempo que tarda el Sulfato de Magnesio en impregnar los centros corticales correspondería al tiempo que transcurre entre la postura de la inyección intra-raquídea y la aparición del estado de somnolencia, siendo tanto más prolongado este estado cuanto mayor sea la impregnación de las células corticocerebrales por el Sulfato de Magnesio; ahora bien, esto depende de varios factores entre ellos tenemos la velocidad con que se haga la inyección intra-raquidea, la presión a que se encuentre el líquido céfalo-raquídeo. Según algunos autores, "la acción del ión magnesio es debida a acción mesoencefálica, puesto que ella se obtiene en conejos previamente decorticados".

Pero el Sulfato de Magnesio no sólo obra sobre los centros nerviosos sino también sobre las prolongaciones de la célula nerviosa, así vemos que inyectado en el trayecto de un nervio actúa suprimiendo su conductivilidad, la cual recupera el nervio apenas se elimina el magnesio, Meltzer aplicando este cuerpo sobre el ganglio simpático superior y sobre la sustancia cerebral, ha producido estados comatosos. La desasimilación lenta de este medicamento nos explica por qué la paciente no recupera su estado consciente de un solo golpe sino gradualmente; o sea que a medida que el sistema nervioso se va desembarazando del Sulfato de Magnesio, va recobrando sus funciones. Algunas pacientes han durado hasta 48 horas después de salir del estado de somnolencia para llegar al estado lúcido completo. Por todas estas propiedades se ve pues, que la inyección intra-raquidea de Sulfato de Magnesio es la ideal para suprimir las convulsiones eclámpticas, bajar la presión arterial y de esta manera suprimir la cefalalgia que tanto ator menta a las pacientes; además, el estado de somnolencia lo aprovecho para desintoxicar el organismo, ya que como se ha demostrado, la eclampsia no es más que una autointoxicación. Con este fin, he establecido el tratamiento de eclampsia de la siguiente manera:

10--Inyección intramuscular de dos amp. de necrotón cada 24 horas. El necrotón como bien sabemos no es otra cosa que el principio antinecrótico de Irorlus, del cual, cada ampolla contiene dos miligramos y medio. Estas inyeccio wes las suspendo cuando noto franca mejoría de la paciente.

2.- - Inyectar en flebodisis, inmediatamente después de entrar en somno lencia 1.000 c.c. de suero dextrosado al $5 \%$ en agua destilada. Prefiero el Suero 
en agua destilada y no en suero fisiológico porque el cloruro de sodio al ser eliminado por el riñón contribuiría a agravar sus lesiones y caso que se dejara de eliminar quedaría retenido por los tejidos con el consiguiente aumento de los edemas.

El fin que me propongo al invectar el suero es el de disolver los diferentes tóxicos al mismo tiempo que diluírlos para que éstos sean eliminados fácil y rápidamente por la orina. Debe vigilarse atentamente a la paciente por si llega a producir parálisis vesical y entonces se impone el cateterismo cvacuador. El suero en feboclisis lo repito durante 3 o 4 días según el estado de la paciente.

$3^{\circ}$-Dieta absoluta durante las 24 horas que siguen a la invección intraraquidea; al cabo de las cuales, dieta hídrica; y dieta líquida en las siguientes 24 horas es decir, té, café con leche, leche, etc. Esta dieta la sostengo hasta tanto la paciente no esté completamente restablecida para ir volviendo lentamente a la alimentación corriente, ordenando a las pacientes que sus comidas deben hacerlas con poca cantidad de sal (cloruro de sodio). Con este tratamiento he obtenido éxito en todos mis casos y creo que este tratamiento llegue a salvar casos que ya se consideren perdidos, ya que dos de los míos eran considerados como tales.

La duración del estado de somnolencia presentado por las pacientes después de la aplicación del sulfato intra-raquídeo varía de 7 a 12 horas. El estado de somnolencia (coma, dice el Dr. Arnedo) aparece una hora u hora y me dia después de la inyección de sulfato.

$4^{\circ}$-inmediatamente la paciente llega, debe hacerse un enema evacuador el cual se repetirá a las 12 horas y aún después a las 24 horas. Si la paciente no hace deposición diaria debe hacerse un enema diario, y después tratar el estreñimiento crónico.

Antes de exponer las conclusiones a que he llegado por la observación de mis casos expongo los casos clínicos que traté. todos ellos en el Servicio de Maternidad del Hospital Santa Clara de Cartagena.

\section{OBSERVACION N? I}

Nombre: M. R. Edad: 30 años. Natural: Cartagena.

Color: Negro: Residencia: Terncra.

Número de partos: Primigestantc. Estado civil: Casada.

Fecha de entrada: Enero 549

Antecedentes familiares Sin importancia.

Aniecedentes personales: Sin importania

Obstetricos-Cimecologicos: Menargua a los 15 años. Reglas tipo 3, 28.

Anumesis: Nuestra pacienteno manifiesta una intensa cefalalgia que no ha logado dominar con ninguno de los preparados comerciales tan alabados para tal fin. Esta cefalalgia hace aproximadamente unos tres meses que le comenzó, calmándose y hasta desipareciendo a vece para retornar nuevamente. Acusa un 
dolor en el epigastrio. Niega trastornos de la visión, diciendo en cambio que no oye bien, siente un zumbido constante en los oídos creyendo que iría a quedarsc sorda, también acusa calambres en las extremidades inferiores.

A la inspección se nota un edema blando generalizado, es un verdadero anasarca; al interrogarla sobre el particular dice que desde el $5^{\circ}$ mes de embarazo comenzó a hincharse empezando por los pies y poco a poco se fue generalizando a todo el cuerpo. La presión da el siguiente resultado: Mx. - 190. - Mn. - 120. mm. de $\mathrm{Hg}$.

Se deja en el Servicio de Maternidad, cama № 23; y se ordena dieta liquida, enema glicerinado e inyectar amp. de Necrotón doble. En la tarde del día 5 de enero tuvo una convulsión. Hubo mordedura de la lengua y del labio superior la convulsión se repitió en la manana del día 6. Fui llamado por los Internos de guardia y ordené el traslado de la paciente a la sala prenatal para hacerle el tratamiento con el Sulfato de Magnesio. Hice sentar a la paciente en la camilla debido a que en decúbito lateral quedaba muy difícil localizar las apófisis espinosas por el gran edema; la paciente además no podía flexionar bien la columna. Después de aseptizar bien la región hice la punción en el cuarto espacio intervertebro-lumbar e inyecté 5 c.c. de la solución; terminada ésta ordené a la paciente se acostara en la camilla y permanecí atento observándola. Cinco minutos después de haberla inyectado, dijo que se le había quitado el dolor de cabeza. 30 minutos después, dijo que se sentía mareada e intentaba sentarse, hacía esfuerzos por hablar y poco a poco fue entrando en estado de somnolencia.

La respiración se hizo fuerte estertorosa y había bradicardia ya que la frecuencia del pulso era de 52 pulsaciones por minuto. La presión arterial bajó: la Mx. $150 \mathrm{~mm}$. y la Mn. 100. Ordené inyectarle en fleboclisis 1.000 c.e. de suero dextrosado al $5 \%$ en agua destilada, inyectar dos amp. de Necrotón in. tramuscular un enema glicerinado y dieta absoluta.

El período somnolencia duró diez horas, al cabo de las cuales empezó a hablar frases incoherentes. Tuvo vómitos y tenía una alegria tranquila que manifestaba cantando y riendo. En este estado de semi-inconsciencia permaneció sin que hubiese manifestaciones de agitación hasta el día 11 en la mañana; este mismo día empezó el trabajo de parto y tuvo parto gemelar; los fetos nacieron. vivos, pero murieron 24 horas después del parto. En el segundo feto hubo que aplicar forceps debido a inercia uterina, trasladada la paciente a su lecho se le siguió el tratamiento antitóxico con Necrotón, suero en hipodermoclisis y enemas evacuadores. Se presentó parálisis vesical por lo cual hubo que practicar cauterismo durante tres días. Támbién hubo paresia intestinal pero cedió sin tratmic wo especial.

II día 12 reaparecieron las ideas incoherentes; la paciente sostenía conversa(wone, con personas que no estaban presentes; en este estado esturo hasta el día 17 en que recobró completamenté el conocimiento. Ya los edemas habían desa parcido. Esta paciente fue dad de alta por estar en aparente buen estado de salud el dia 20 de enero. Las convulsiones no se repiticron después de la in 
yección intra-raquídea de Sulfato de Magnesio.

Exámenes de Laboratorio: De orina. Fecha: Enero $7 / 49$.

Densidad: 1.021. Albúmina: Trazas. Cilindros: no.

Orina: enero 11. Densidad: 1.008. Albúmina: Trazas. Leucocitos: x Los demás elementos: Normales.

Orina: Enero 18/49. Densidad: 1.010. Albúmina: Trazas. Leucocitos: xxxx Los demás elementos: Normales.

\section{OBSERVACION N! 2}

Nombre: J. B. de la R. Edad: 19 años. Natural: Cartagena.

Color: Negro. Número de partos: Primigestante. Estado civil: Casada.

Fecha de entrada: Febrero $21,49$.

Antecedentes patológicos familiares: Sin importancia.

Personales: Sin importancia.

Obstétricos-Ginecológicos: Menarquia a los 15 años. Vida marital a los 18 . Edad del embarazo: 7 y medio meses.

Anamnésis: Refiere la paciente que desde el día 15 de febrero aproximadamente comenzó a sentir mareos los cuales se repetían diariamente y cada vez con mayor intensidad. Niega haber tenido dolor en el epigastrio, ni edemas; refiere que el día en que aparecieron las convulsiones, la cefalalgia se intensificó más que nunca. Micción y deposiciones dice que eran normales. Refiere que veía "estrellitas" (escotomas), y casi todos los días tenía zumbidos de oído.

El día 20 a las 10 p. m. tuvo la primera convulsión y por esto fue traída a! hospital, donde fue atendida por los Internos de Guardia. Pasada esta primera convulsión regresó a su casa, pero a la una de la madrugada del día 21 tuvo otra convulsión por lo cual la trajeron nuevamente al hospital y se ordenó entonces su hospitalización en el servicio del doctor Juan Barrios Zapata; estando ya hospitalizada tuvo una nueva convulsión. A llegar a la Maternidad el día 21 fui notificado del caso; la paciente estaba en estado comatoso. Procedí a examinarla y halle la presión arterial así: Mx: 150 y Mn: $100 \mathrm{~mm}$. Pulso 125 pulsaciones por minuto. No había edemas. Hice trasladar la paciente a la Sala de exámenes y le puse un abre-boca para impedir que se volviese a morder la lengua si se llegaban a repetir las convulsiones; ya en esta sala recobró el conocimiento; con testaba bien a las diversas preguntas que se le hacían; dijo que no recordaba nada de lo que le había pasado. Como hubiesc facilidad para hacer la punción en decúbito lateral, la dejé en esta posición. Hice la punción en el cuarto espacio intervertebro-lumbar con gran facilidad a las $11.30 \mathrm{a}$. m. Hecha la punción inyecté los 5 c.c. de la solución de Sulfato de Magnesio al 20\%; dure un minut inyectándole el líquido. Ocho minutos después dijo que se había aliviado el dolor de la cabeza y fue entrando gradualmente en un sopor profundo. Treinta minutos después de la invección estaba en estado de profundo sueño; su res. piración ere normal; el pulso descendio a las 90 pulsaciones al minute y la presión arterial también bajo asi: $120 \mathrm{mmg}$. $1 \mathrm{x}$ y $85 \mathrm{Mn}$. En cste estado fue 
trasladada a la cama; así permaneció en este estado de somnolencia durante 10 horas o sea que a las 10 p. m. empezó a recobrar el conocimiento; reconocía a todos los familiares que se hallaban a su alrededor. Inmediatamente después de la invección intra-raquídea ordené el tratamiento antitóxico ya conocido, es decir, invección i. v. de 1.000 c.c. de suero dextrosado al $5 \%$ en agua destilada; inyectar intramuscularmente dos amp. de Necrotón; hacer enema cvacuador y vigilarla. La dieta se la indiqué en la forma va conocida, es decir, 2t horas de dieta absoluta; en las 24 horas siguientes dieta liquida (té, café con leche, etc.), prolongando ésta hasta el total restablecimiento de la enferma.

Hubo parálisis vesical la cual cedió rápidamente con el tratamiento y"? indicado. No hubo vómito, ni agitación; de vez en cuando ré́a con gran en tusiasmo y empezó a relatar su vida pasada creyendo que hablaba con su esposo. Ya por la tarde todo estaba normal y la paciente se sentía tan bien que pidió la salida. Sin embargo, la retuve en él Servicio hasta el día siguiente.

El feto estaba vivo. Se le dio de alta el día 25 de febrero con la indicación que debía pasar al Servicio cada 10 días para examinarla. La eclampsia no se repitió y el embarazo llegó a término habiendo parido en el Servicio el día $1^{-}$ de abril.

Exámenes de Laboratorio: De orina (febrero 21/49) Densidad: 1.017. Pigmentos biliares: Trazas. No había cilindros ni albúmina. Todos los demás elementos, normales.

Dosificación de la Urea sanguínea: (febrero 21/49). $65 \mathrm{mg}$. \%. La toma de sangre se hizo antes de inyectar el Sulfato de Magnesio.

Urea sanguinea: (febrero 23/49), $48 \mathrm{mg}$. \% (La toma de sangre, 19 horas después de la inyección de Sulfato de Magnesio).

\section{OBSERVACION No 3}

Nombre: C. F. Edad: 18 años. Color: Negro.

Natural: Maria la Baja. Número de partos: Primigestante.

Estado civil: Casada. Edad del embarazo: 9 meses.

Fecha de entrada: Febrero 26/49.

Antecedentes familiares: Sin importancia.

Antecedentes personales: Sin importancia.

Obstétricos-Ginecológicos: Menarquia a los $1+$ años. Vida marital a los 17 años.

Anammesis: Refiere la paciente que el día 24 de febrero fue presa de una intensa cefalalgia que se calmaba momentáneamente pero no desaparecía. El día 26 ta cefalalgia se acompaño con dolor en el epigastrio, es decir, el clásico holor en barra de Chaussier. No presentaba sintomatologia auditiva u optica. 1 los 7 meses de embrazo dice que se le hinchar n los pies (edemas maleolares); este edema no desaparecia; orinaba y defecaba nomalmente. El día 26 los deteres aumentaron por 1 coul fue traida al Hospital al Servicio de Emergen (ia, a las 5 a. m. Los internos de Guardia ordenamo hospitalizarla; ya en el 
Servicio del doctor Zapata tuvo una convulsión a las 11 a. m. Entonces fui llamado. Procedí a examinarla. Como síntomas sobresalientes hallé un edema blando de los pies y las piernas; estaba en semicoma; 130 pulsaciones por minuto; presión arterial de $160 \mathrm{Mx}$ y $100 \mathrm{Mn}$. Mientras estuve examinándola turo otra convulsión, después de la cual, quedó en coma. Ordené que la pasaran a la camilla. Después que había salido del coma procedí a inyectar intra-raquídeamente los 5 c.c. de Sulfato de Magnesio al 20\%. Duré invectando la solución 1 minuto. Terminé de inyectar la solución a las $6.30 \mathrm{p}$. m. A las 6.45 p. m. ya había desaparecido la cefalalgia, según dijo la paciente. Manifestó que sentía muchas ganas de dormir y gradualmente fue entrando en estado de hipnosis, el cual fue completo a las $10 \mathrm{p}$. m. Trasladada a su cama ordené el tratamiento ya conocido, o sea el mismo que le hice a las dos pacientes anteriores. La presión arterial a las $10 \mathrm{p}$. m. era la siguiente: $\mathrm{Mx} 110 \mathrm{~mm}$. y Mn. $90 \mathrm{~mm}$. A las 3.30 a. m. del día 27 fue llamado porque las convulsiones se repitieron, ordené un abre-boca y enema evacuador. A las 8 a. m. del día 27, la paciente estaba en completo estado de lucidez y comenzó trabajo de parto Nota: a esta paciente no se le inyectó el suero después de la inyección intraraquídea, porque no lo había en el hospital. Por la tarde hubo ligera agitación y una hipertermia que llegó a 38.7 grados; el trabajo de parto continuaba normalmente y por la noche a las 11 hubo necesidad de aplicarle un forceps bajo debido a que el feto no progresaba y hubo expulsión de meconio. El resultado fue bueno tanto para el feto como para la madre; se hizo extracción de la placenta y luégo hubo una hemorragia abundante debido a retención de membranas; se hizo legrado digital y la hemorragia cesó. Ordené suero dextrosado en fleboclisis ( 500 c.c.), inyecciones de ergotina, y continuación del tratamiento antitóxico.

Exámenes de Laboratorio: A esta paciente sólo se le hizo dosificación de urea sanguínea porque ingresó al Servicio un sábado y el Laboratorio permanecía cerrado hasta el lunes. Agradezco al doctor Almario, la gentileza de haber hecho el examen de la dosificación de urea sanguínea. Urea sanguínea 100 mg. \%. (Febrero 27/49). Se le dio de alta el 7 de marzo en aparente buen estado de salud.

\section{OBSERVACION NO 4}

Nombre: L. C. Edad: 40 años. Natural: Santa Rosa.

Color: Blanco. Residencia: Turbaco. Número de partos: 12. Abortos: 3. Estado civil: Casala. Fecha de entrada: Marzo 5/9.

Antecedentes personales: Sin importancia.

Obstétricos-Ginecológicos: Menarquia a los 13 anos. Vida marital a los 15 años. Eclampsia en el 7" embarazo.

Edad de embonazo: (ando ingreso a la Matemidad, hacía 12 horas que habia parido. 
Anamnésis: El dia 5 de marzo a las 4 a. m., fui llamado al Servicio de Maternidad por orden del Interno de Guardia. Al llegar encuentro una señora en estado comatoso con la boca ensangrentada por mordeduras en la lengua y los labios.

Trismus, miosis, pulso rápido, 130 pulsaciones por minuto, fuerte y lleno A la auscultación se nota el ruido de galope; no hay soplos; la presión arterial da: $180 \mathrm{mmg}$. y Mn de $100 \mathrm{~mm}$. Diagnóstico: Eclampsia. Se le extrae sangre para dosificación de urea y orina con sonda para examen.

Interroguć a la mamá quien dijo que a las 4 p. m. del día 4 de marzo dio al luz aparentemente bien; poco después se quejó de un fuerte dolor en cl estómago (dolor epigástrico) mareo y decía que veía "estrellitas".

A las 12 de la noche tuvo la primera convulsión, entonces resolvieron traerla al Hospital. En el camino de Santa Rosa a Cartagena, tuvo otra convulsión, Pregunté sobre el estado de la paciente antes de parir y me dijo la madre que se quejaba continuamente de dolor de cabeza, continuas fatigas y de dolor de estómago pero que nunca se había hinchado. Procedí a inyectar los 5 c.c. de solución de Sulfato de Magnesio al 20 por ciento a las 5 a. m Tiempo que duré inyectando 1 minuto. La hice trasladar a su cama y ordené el tratamiento que ya indiqué de suero dextrosado, enemas evacuadores, dieta y necrotón. La paciente no entró en hipnosis. La presión arterial se modificó así: Mx 120 y Mn. $85 \mathrm{~mm}$. Pulso: 100 por minuto. Tenía un continuo mo vimiento de lateralidad de la cabeza. La convulsión se repitió a las 3 p. m., entonces ordené inyectarle una Amp. de l ctgrm. de Clorhidrato de Morfina. A las 2 a. m. el pulso se hizo rápido, débil, pequeño; hubo lipotimia; inyecté una Amp. de Coramina; como el estado general no mejoraba y el pulso continuaba débil le inyecté una Amp. de Adrenalina y ordené ponerle bolsas tibias en la región precordial. La paciente reaccionó; el tratamiento antitóxico se continuó por 6 días. Hubo parálisis vesical y cefalalgia intensa por espacio de 4 dias después de la inyección intra-raquídea. Al séptimo día todo se había normalizado y la paciente pidió se le diera de alta. Se le dio de alta el día 16 de marzo en aparente buen estado de salud.

Examenes de Laboratorio: De orina: Marzo 5/49. Densidad: 1.009. Pig. mentos biliares: Trazas. Cilindros granulosos: x. Cilindros hialinos: xx. Albúmina: xxx.

Dosificación de urea sanguinea: Marzo 6/49. $100 \mathrm{mmg}$. \%. Trazas

Examen de orina: (Marzo 10/49). Densidad 1.015. Pigmentos biliares: males

Cilindros granulusos: No. Cilindros hialinos X. Demás elementos, Nor-

Urea sanguinea: (Marzo 10 49) $50 \mathrm{mmg}$. \%. Un examen de orina hecho d dia 14 de marzo era completamente normal. 


\section{OBSERVACION No 5}

Nombre de la paciente: J. P. Edad: 19 años. Natural: Arjona.

Color: Negro. Número de partos: es primigestante. Estado civil: Casada. Edad del embarazo: 9 meses. Fecha de entrada: Marzo 10/49.

Antecedentes familiares y personales: Sin importancia.

Obstétricos-Ginecológicos: Menarquia a los 12 años. Vida marital a los 18 años.

Anamnésis: La paciente que hoy me ocupa ingresó al Servicio del doctor Barrios Zapata el día 10 de marzo por tener edemas en las extremidades inferiores y tener una persistente cefalalgia desde el comienzo de su embarazo que nada había podido calmar; tenía entonces 8 meses de gestación; T. A.: Mx. $170 \mathrm{~mm}$. y Mn. $100 \mathrm{~mm}$. Acusa vértigos y trastornos de la visión. No ha habido vómitos, ni dolor epigástrico, ni convulsiones.

Diagnóstico: Preeclampsia. Se ordena examen de orina y dosificación de urea sanguínea. El primero fue normal y el segundo fue de $65 \mathrm{mmg}$. \%. Se le hace tratamiento con suero dextrosado en hipodermoclisis, enemas evacuantes y laxantes. El cuadro se modificó favorablemente, pero reapareció cuatro días después; en estas alternativas de mejorías y recaídas duró hasta el día 10 de abril en la mañana cuando fui llamado porque la paciente había tenido una convulsión. Al hacer el examen encuentro, ligero edema maleolar. Presión arterial Mx: $170 \mathrm{~mm}$. Mn: $120 \mathrm{~mm}$. La paciente estaba en estado comatoso, no había mordedura de la lengua; la frecuencia del pulso era de 110 por minuto. El feto estaba vivo; había contracciones uterinas, rítmicas y fuertes por lo cual ordené su traslado a la Sala Prenatal; estando aquí recobró el conocimiento, la interrogué y dijo que no sabía absolutamente nada de lo que le había ocurrido, es decir, había amnesia para todo lo que le había pasado desde el momento en que tuvo la convulsión hasta que recobró el conocimiento, lo último que recordaba era que tenía un fuerte dolor de cabeza y mareo.

Procedí a inyectar los 5 c.c. de la solución de Sulfato de Magnesio al 20\% intra-raquídeamente durante un minuto, en el cuarto espacio intervertebrolumbar. La punción lumbo-raquidea la hice a las 10 a. m. La paciente lentamente fue entrando en hipnosis hasta quedar completamente dormida una hora después de la inyección. La presión arterial tomada dos horas después de haber invectado el Sulfato de Magnesio dio el siguiente resultado: Mx: $120 \mathrm{~mm}$. y Mn: $100 \mathrm{~mm}$. de $\mathrm{Hg}$. El pulso descendió a 90 pulsaciones por minuto. El trabajo de parto continuaba. La presión arterial a las tres de la tarde daba el siguiente resultado: Mx: $120 \mathrm{~mm}$ de $\mathrm{Hg} \cdot \mathrm{Mn}$ : $70 \mathrm{~mm}$. Pulso 60 . Ausculté el leto y como notara sufrimiento, practiqué un tacto vaginal. Había dilatación completa. Rompi la bolsa de las aguas. Salió liquido amniótico mezclado con meconio por lo que me decidi por una aplicación de forceps. Además, la progresion fetal estaba detenida y la bradicardia fetal continuaba; hice buena toma y todo salio bien; extraccion manual de la placenta. La paciente fue trasladada a su cama y se le comenzo a hacer el tratamicnto antitóxico que describí ante- 
riormente. El feto murió 7 horas después. La paciente salio de su hipnosis a las 5 a. m. del día 11 de abril. El 15 la interrogué y ya se encontraba en plen. estado consciente y no acusaba malestar alguno. Se le dio de alta el día 20 de marzo en aparenté buen estado de salud.

Exámenes de laboratorio: De orina (Marzo 16 49). Densidad: 1.014. (c) lulas epiteliales: $\mathrm{xx}$. Urato de sodio: $\mathrm{x}$.

Examen de Orina (Marzo 21/49). Densidad: 1.010. Albúmina: Trazas. Leucocitos: $x$. Urato de sodio: No. Los restantes elementos: Normales.

Urea sanguínea: Marzo 23/49. $60 \mathrm{mmg}$ x ciento.

De orina: Marzo 29/49. Densidad: 1.010. Albúmina: Trazas. Urea 6 gr. $\mathrm{x}$ lt. Cloruros: $9.5 \mathrm{gr} . \mathrm{x}$ lt. Demás elementos: Normales.

Dosificación de urea sanguínea (Abril 9, 49): $52 \mathrm{mmg}$. \%.

\section{OBSERVACION No 6}

Nombre: E. C. Edad: 19 años. Natural: Cartagena.

Color: Moreno. Número de partos: Primigestante. Estado civil: Casada. Edad del embarazo: 9 meses. Fecha de entrada: 17 de abril de 1949.

Antecedentes patológicos familiares y personales: Sin importancia.

Obstétricos-Ginecológicos: Menarquia a los 12 años. Vida marital a los 18 años.

Anamnésis: La paciente a quien me voy a referir en esta historia llegó a la Sala de Emergencia el día 17 de abril donde fue atendida por los Internos de Guardia quienes diagnosticaron eclampsia y en consecuencia me mandaron a buscar para que me hiciera cargo del caso. Cuando llegué la paciente estaba en estado semi-comatoso, no respondía a las preguntas que le hacía. Noté un ligero edema maleolar y había mordedura de la lengua, interrogada la persona que la trajo al hospital dijo que ya ésta era la cuarta convulsión que le había dado; así mismo nos informó que había roto la bolsa de las aguas y que tenía dolores fuertes de parto. Hice pasar a la paciente a la Sala Prenatal donde le tomé la presión arterial con el siguiente resultado: Mx: 160. Mn: $110 \mathrm{~mm}$. Hg. Frecuencia del pulso: 115 pulsaciones por minuto. A las 10 a. m. del 17 de abril le inyecté los 5 c.c. de la solución de Sulfato de Magnesio al 20 por ciento en un minuto. A las 11 a. m. entro en hipnosis y el trabajo de parto continuaba. Media hora después de la inyección intra-raquídea la presión arterial se habia modificado así: Mx: $120 \mathrm{~mm}$. Mn: 70 . Como el descenso fetal no continuaba y los latidos fetales disminuian de frecuencia procedí a aplicar un forceps bajo con un feliz resultado. La paciente salió del estado de hipnosis a las $8 \mathrm{a} . \mathrm{m}$. del día siguiente. Había amnesia completa para lo ocurrido inmedi tamente des pués que le comenzaron las convulsiones. La cefalalgia desapareció rapidamente. La orina aumentó con bastante rapidez y su estado era muy bueno. La paciente se le dio de alta el día 25 de abril estando en aparente buen estado do salud. No se le practicaron exámenes de Laboratorio. 


\section{OBSERVACION NO 7}

Nombre: P. P. Edad 24 años. Natural: San Antero.

Color: Negro. Residencia: Cartagena. Número de partos: Primigestante. Estado civil: Casada. Fecha de entrada: Mayo +49.

Antecedentes familiares y personales: Sin importancia.

Obstétricos-Ginecológicos: Menarquia a los 14 años. Vida marital a los 23 años.

Anamnésis: A las dos y media de la madrugada del día 4 de mayo fui llamado al Servicio de Maternidad; al llegar tuve la agradable sorpresa que consti tuve un motivo de satisfacción intima al ver que mi Profesor doctor Juan Barrios Zapata, me hacía el honor de entregir a mi cuidado una paciente particular suya para que le aplicara el tratamiento que tanto éxito había tenido en casos anteriores. La paciente estaba en estado comatoso. El diagnóstico ya estaba hecho por el doctor Barrios quien muy gentilmente me suministró los datos sintomatológicos que expongo a continuación. Hacía varios días estaba en li. gero estado edematoso de las extremidades inferiores; tenía el clásico dolor epigástrico en barra de Chaussier; el día 4 turo cefalalgia intensa. Con el fin de calmarlo se puso bolsa de hielo en la cabeza y por la noche se alivió algo habiéndose quedado reclinada en un asiento donde dormía; de pronto quienes la rodeaban se alarmaron al ver que ésta caía inconsciente en el suelo con convulsiones. Inmediatamente llamaron al doctor Barrios y la hospitalizaron; estando ya en el Servicio tuvo dos convulsiones más. Se protegió la lengua con un abreboca. Había taquicardia; la presión arterial: Mx: $170 \mathrm{~mm}$. Mn: $100 \mathrm{~mm} \mathrm{Hg}$.

Procedí a inyectar el Sulfato de Magnesio intra-raquídeo; en posición de decúbito lateral izquierdo. Presentó agitación intensa y raquialgia, vómitos y relajación de los esfinteres. Los latidos fetales eran normales. La invección la puse a las 2 y media a. m. y a las 4 ya la paciente estaba en hipnosis. La presión arterial bajo $\mathrm{Mx}: 150 . \mathrm{Mn}: 85$. Las pulsaciones a 60 por minuto.

La hipnosis sólo duró 6 horas al cabo de las culales la paciente volvió len tamente en sí. Después de la inyección indiqué el clásico tratamiento desintoxicante anteriormente descrito. Todo marchó bien y la paciente se restablecí́ completamente. El dia 9 de mayo fue dada de alta por el doctor Barrios en aparente buen estado de salud; el feto estaba bien, es decir, no había nada anormal que pudiera llamar la atención. Como su estado mejoró rápidamente no se le hicieron pruebas de laboratorio.

\section{OBSERVACION N? 8}

Nombr: N. R. Edad: 28 anos. Natural de Cartagena.

Color: Negro. Numero de partos: 1. Estado civit: Casada. Edad del em barazo: cunndo llegó al Senicio hacia tres días que había parido. 
Antecedentes patológicos personales y faniliares: Sin importancia.

Obstétricos-Cinecológicos: Menarquia a los 16 anos. Vida marital a los 20 años.

Anamnésis: El día 7 de mayo encontré en el Servicio de Maternidad a las 8 a. m. a una paciente en estado comatoso . La madre nos dio estos datos: la paciente tenía edema de los miembros inferiores antes del parto pero que después desaparecieron; pero encambio se le presento cefalalgia resistente a los calmantes, vómito y dolor epigástrico.

El lunes a las 7 de la mañana tuvo la primera convulsión; entonces la trajeron a Maternidad donde tuvo dos convulsiones más. La presión arterial era: Mx: 180 y Mn: $120 \mathrm{~mm}$ de Hg. Había una pronunciada taquicardia. A las 8-45 minutos inyecté la solución de Sulfato de Magnesio (5 c.c.) al $20 \%$ durante un minuto intra-raquídea. La paciente fuc entrando lentamente en hipnosis y a las 11 a. m. ya estaba en sueño profundo. Vigilé muy atentamente que se cumpliera el tratamiento antitóxico debido a que su estado era bastante grave. Permaneció 15 horas al cabo de las cuales volvió en sí, pero su estado consciente no era completamente lúcido. Empezó a hablar sola y no reconocía a sus familiares acusándoles de ser responsables de su enfermedad. Al segundo dia después de la inyección recobró completamente el conocimiento. Inmediatamente después de la inyección intra-raquídea, la presión bajo y la frecuencia del pulso se normalizó. Ultimamente se quejaba de raquialgia, de incontinencia de orina y de un dolor en el periné. Todos estos sintomas desaparecieron con el tratamiento antiespasmódico y con la inyección de calcio (gluconato y cloruro) Esta paciente fue dada de alta en aparente buen estado de salud el día 12 de mayo. Exámenes de Laboratorio: De orina (Mayo 3/49). Densidad: 1.023. Cilindros granulosos: xxx. Los demás elementos: Normales.

Urea de la sangre (Mayo 3/49): $68 \mathrm{mmg}$. por ciento.

\section{RESUMEN ESTADISTICO}

Los 8 casos observados por mí se pueden resumir asi: 6 casos de eclamp sia en primigestantes de las cuales cuatro eran menores de 20 años; una de $2+$ y la otra de 30 años.

Dos casos de eclampsia en puérperas, de las cuales una cra multípara y la otra primigestante; con 40 y 22 años, respectivamente.

Siete de las pacientes totales entraron en hipmosis profunda de media a una hora después de la inyección intra-raquidea; y la otra que fue la mulipam de 40 años sólo entro en hipmose cinco horas de ace de la ingeción intrat raquidea. En todas 8 descendio la presion arteria!! hubo bradicardan. Sicte de has 8 pucientes duraron en hipmosis alrededor a 10 horas, la otra solo dura cinco horas.

En todos los casos dure un minuto invectando la solucion de Sullato de Magnesio. 


\section{O N C L U S I O N E S}

1.-El Sulfato de Magnesio en solución al 20\% ( 5 c.c.) suprime las convulsiones eclámpticas, debido a su acción depresora sobre el sistema nervioso, manifestándose esta acción rápidamente cuando se inyecta intra-raquídeo.

II.-Origina una profunda hipnosis que empieza aproximadamente una hora después de la inyección y dura aproximadamente diez horas, tiempo aprorechable para desintoxicar el organismo.

III.-Siendo como en efecto es la Eclampsia una intoxicación múltiple, es decir, no específica, no solamente hay que suprimir las convulsiones sino que se debe poner en práctica todos los medios posibles para desintoxicar la paciente.

IV.-Las convulsiones no se repiten si el tratamiento se hace en la forma que he descrito.

V.-La presión arterial baja siempre.

VI-En todos mis casos, la cantidad de orina emitida en las 24 horas aumentó rápidamente, prueba esta de que la paciente mejoraba.

VII.-No hubo un solo caso de mortalidad materna; todo respondieron ra pidamente al tratamiento; los casos más graves fueron los de Eclampsia Puerperal.

VIII.-Los edemas desaparecieron rápidamente.

IX.-En los casos que tuve de eclampsia durante el parto, e! Sulfato de Magnesio no manifestó acción alguna sobre la contracción de la fibra uterina: ya que el trabajo de parto continuó sin interrupción.

X.-En ninguno de los casos hubo necesidad de repetir la inyección intraraquídea.

XI.-Es un método de fácil ejecución que se puede llevar a cabo en cualquier parte.

XII.-Una de las principales ventajas del método la constituye el hecho de que no es necesario evacuar el útero; antes por el contrario, le permite al médico conducir la gestación hasta el término. el feto.

XIII.-El Sulfato de Magnesio no ha manifestado acción alguna sobre

XIV.-La única objeción que se podría hacer al método son los accidentes a que expone la punción lumbar. Debo confesar que teniendo cierta pericia no es de temerlos. En mis pacientes sólo observé vómitos, raquialgia, ligera agitación, relajación de los esfínteres, síntomas éstos que son fugaces y no encierran ningún peligro.

B I B L I O G R A F I A

Obstetricia

Compendio de Obstetricia

Técnica Quirúrgica

Anatomia Humana

Tratado de Obstetricia
Fabre.

Enest Bumm.

Carlos E. Ottolenghi y otros.

Testut Latarjet.

A. Doderlein. 